\title{
sciendo
}

\section{A NON-SYNONYMOUS SINGLE NUCLEOTIDE POLYMORPHISM IN FASN GENE ALTERS FASN ENZYME ACTIVITY IN SUBCUTANEOUS AND INTRAMUSCULAR ADIPOSE TISSUE IN HOLSTEIN FRIESIAN STEERS*}

\begin{abstract}
David Cancino-Baier ${ }^{1,2}$, Erwin Muñoz ${ }^{3}$, John Quiñones ${ }^{1,4}$, Jorge F. Beltrán ${ }^{4}$, Fernanda Fuentes ${ }^{3}$, Jorge Farías ${ }^{4}$, José Manuel Lorenzo ${ }^{5}$, Rommy Diaz 6 , Karla Inostroza ${ }^{1}$, José Bento Sterman Ferraz ${ }^{7}$, Néstor Sepúlveda ${ }^{1,8}$
\end{abstract}

${ }^{1}$ Centro de Tecnología e Innovación de la Carne, (CTI Carne-CEBIOR-BIOREN). Universidad de La Frontera, Temuco, Chile

${ }^{2}$ Escuela de Medicina Veterinaria, Facultad de Ciencias, Universidad Mayor, Chile ${ }^{3}$ Centro de Excelencia de Biotecnología en Reproducción (CEBIOR),

Universidad de La Frontera, Temuco, Chile

${ }^{4}$ Departamento de Ingeniería Química, Facultad de Ingeniería y Ciencias,

Universidad de La Frontera, Temuco, Chile

${ }^{5}$ Centro Tecnológico de la Carne de Galicia, Galicia, España

${ }^{6}$ Departamento de Ciencias Básicas, Facultad de Medicina, Universidad de La Frontera, Temuco, Chile

${ }^{7}$ Grupo de Melhoramento Animal, Departamento de Ciências Básicas, Faculdade de Zootecnia

e Engenharia de Alimentos, Universidade de São Paulo, Pirassununga, SP, Brasil

${ }^{8}$ Facultad de Ciencias Agropecuarias y Forestales. Universidad de La Frontera, Temuco, Chile

•Corresponding author: cancinobaier@gmail.com

\begin{abstract}
The FASN enzyme plays a key role in fatty acids synthesis as the main long-chain fatty acid synthesizer. A non-synonymous SNP (single nucleotide polymorphism) (g.17925A $>$ G) located in the thioesterase domain of this enzyme and an effect in fat deposition has been observed, but has not been evaluated in this breed and, moreover, the reason whereby this occurs remains unclear. The objective of this study was to evaluate the effect of this SNP on the activity of FASN enzyme in subcutaneous and intramuscular adipose tissue from Holstein Friesian steers. To achieve this, 196 animals were sampled in a local abattoir, genotyped for the $F A S N$ g.17924A $>$ G SNP and characterized for fatty acid profile. Then a sub-sample of 20 animals per genotype were selected to extract the total protein from subcutaneous and intramuscular adipose tissue to estimate the FASN enzyme activity. The FASN activity for each genotyped animal was assessed indirectly by measuring the decrease in the absorbance of NADPH at $340 \mathrm{~nm}$ by spectrophotometry in a 24 well plate in the presence of Acetyl-CoA, Malonyl-CoA, and NADPH. To assess the impact of SNP induced amino acid changes in FASN protein structure, in-silico simulations were performed. Our results indicated that FASN g.17924A $>$ G SNP induces a change in the enzyme activity in subcutaneous adipose tissue, which is higher when the $\mathbf{A A}$ genotype is present and lower in the presence of the
\end{abstract}

\footnotetext{
*Work financed from: National Doctorate Grant CONICYT: 21151048.
} 
AG genotype. The in-silico analysis of the amino acid substitution shows that there was a structural change in the dimeric form of the protein between genotypes. Moreover, the global energy between subunits is lower and more favorable when the A A genotype is present and higher and less favorable for the AG genotype. It was also found that the fatty acid profile of subcutaneous adipose tissue was affected when the AG genotype was present, decreasing the C16:0 fatty acid levels and increasing the C18:0 fatty acid levels. The FASN g.17924A>G SNP alters the FASN enzyme structure and activity, leading to a variation in the fatty acid composition of subcutaneous adipose tissue in Holstein Friesian steers. Implications: This SNP could be considered as a tool to improve the fat deposition or marbling and the fatty acid profile in cattle.

Key words: Bos taurus, adipose tissue, enzyme activity, fatty acids, FASN

Holstein Friesian is the principal dairy breed in Chile (Ostrowski and Deblitz, 2001). The genetics of this breed has an influence in almost $50 \%$ of the country cattle population while surplus males from dairy farms supply up to $70 \%$ of local meat production (Navarro and Goic, 2003). However, the carcass and meat quality are lower in comparison to other meat breeds, mainly as a result of poor backfat deposition and lower marbling, resulting in reduced overall carcass value (Choi et al., 2000; Paris et al., 2015). Among the factors which regulate fat deposition in cattle, genetics plays a major role (Jeong et al., 2012). Previous studies using Holstein breed cattle have focused on milk production traits without placing emphasis on meat quality traits such as marbling (Ng-Kwai-Hang et al., 1986; Rodríguez-Bermúdez et al., 2017).

The main lipogenic gene that has been evaluated in Holstein breed is the fatty acid synthase (FASN) which plays a key role in de novo fatty acid synthesis (Ciecierska et al., 2013). In non-lactating ruminants, adipose tissue is the main lipogenic site and has the highest expression level of FASN gene (Roy et al., 2005). FASN encodes for a multifunctional protein complex with seven different catalytic sites, with the thioesterase domain determining the length of the synthetized fatty acids (Zhang et al., 2008). Functional FASN is a dimeric protein that is responsible for de novo fatty acid synthesis, in particular of saturated fatty acids (SFA) including myristic acid (C14:0) and palmitic acid (C16:0) (Zhang et al., 2008). The FASN gene has been associated with fat deposition in several beef cattle breeds (Jeong et al., 2012; Papaleo Mazzucco et al., 2016), and with milk fat composition in dairy cattle breeds (Alim et al., 2014), but there is no information about its role in the quality of meat from Holstein Friesian steers. Many single nucleotide polymorphisms (SNPs) have been identified within the FASN gene (Raza et al., 2018; Zhu et al., 2017), but the $F A S N$ g. 17924A $>\mathrm{G}$ is the only non-synonymous SNP present in the thioesterase domain (Bhuiyan et al., 2009). This SNP has been reported to influence the fat content and fatty acid composition of milk, but its potential effects on meat quality and fat deposition remain unclear in Holstein cows (Matsumoto et al., 2012). Moreover, there is no information about the effect of this SNP on FASN enzyme activity in adipose tissue from this breed. Therefore, we have hypothesized that SNP g.17924 A $>$ G alters the FASN enzyme activity due to a structural modification induced by the amino acid substitution in the thioesterase domain. We evaluated the effect of the FASN g.17924A>G SNP in relation to enzyme activity from samples of 
subcutaneous (SAT or backfat) and intramuscular adipose tissue (IAT) in Holstein Friesian steers and assessed the effect of the amino acid substitution in the enzyme structure.

\section{Material and methods}

This study was carried out under the protocol for animal care approved by the Scientific Ethical Committee of Universidad de La Frontera, Temuco, Chile (Protocol number: 033-17).

Samples of the longissimus muscle and subcutaneous adipose tissue were collected from 196 Holstein Friesian steers that were slaughtered at the "Planta Faenadora de Carnes Victoria S.A”, located in Victoria, Araucanía region, Chile, 4720897. Samples were quickly frozen in liquid nitrogen and then stored at $-80^{\circ} \mathrm{C}$ until DNA and total protein extraction was carried out. Steers were the same age (18-month-old) and were raised under the same conditions by a local dairy farm "Agricola Ancali", Los Angeles, Bio-Bio region, Chile.

\section{DNA extraction and SNP genotyping}

Each animal was genotyped for the $F A S N$ g.17924A $>$ G SNP through PCR-RFLP technique using genomic DNA obtained from muscle using a commercial kit (Cat. \#D3024, Quick-DNA Miniprep kit, Zymo Research, California, USA). PCR was performed in a total volume of $50 \mu \mathrm{L}$ containing: PCR Buffer $1 \mathrm{X}$, dNTPs $(0.8 \mathrm{mM})$, primers (10 ng of each) (forward ${ }^{5}$ AGAGCTGACGGACTCCACAC ${ }^{3}$ 'and reverse ${ }^{5}$ CTGCATGAAGAAGCACATGG ${ }^{3}$ ), Paq5000 polymerase $(2.5 \mathrm{U}), 37 \mu \mathrm{L}$ of nuclease-free water and $50 \mathrm{ng}$ of genomic DNA. Amplifications were performed using the Paq5000 DNA Polymerase (Cat. \#600680, Agilent Technologies, California, USA) protocol as follows: initial denaturation at $95^{\circ} \mathrm{C}$ for $2 \mathrm{~min}, 30$ amplification cycles (denaturation at $95^{\circ} \mathrm{C}$ for $20 \mathrm{~s}$, annealing at $56^{\circ} \mathrm{C}$ for $20 \mathrm{~s}$ and extension at $72^{\circ} \mathrm{C}$ for $30 \mathrm{~s}$ ) and a final extension period at $72^{\circ} \mathrm{C}$ for $5 \mathrm{~min}$. The $759 \mathrm{bp}$ amplicon obtained was then digested by the restrictase MscI (Cat. \#R0534S, New England Biolabs, Massachusetts, USA) which included CutSmart buffer 1X, MscI restriction enzyme (3 U), $6.4 \mu \mathrm{l}$ of nuclease-free water and $10 \mu \mathrm{l}$ of PCR product $(10 \mathrm{ng} / \mu \mathrm{l})$ in a total volume of $20 \mu \mathrm{l}$ at $37^{\circ} \mathrm{C}$ in an overnight reaction and then submitted to agarose gel electrophoresis $(1.5 \% \mathrm{~W} / \mathrm{V})$. The $759 \mathrm{bp}$ amplicon containing the AA genotype presented 3 fragments including $342 \mathrm{bp}, 251 \mathrm{bp}$ and $166 \mathrm{bp}$, the AG genotype 4 fragments including $417 \mathrm{bp}, 342 \mathrm{bp}, 251,166$, and the GG genotype 2 fragments including $417 \mathrm{bp}$ and $342 \mathrm{bp}$ (Figure $1 \mathrm{~A}$ ).

\section{Protein extraction by ultracentrifugation}

Total protein extraction was performed according to Kumar and Dodds (1981). Briefly, $5 \mathrm{~g}$ of the longissimus muscle and subcutaneous adipose tissue samples from each steer $(\mathrm{n}=20$ per genotype) were homogenized in $38 \mathrm{~mL}$ of phosphate-bicarbonate buffer (0.1M and $\mathrm{pH}: 8.0)$, then centrifuged at 20,000 $\mathrm{g}$ for $10 \mathrm{~min}$, and the supernatant was transferred to a polypropylene tube which underwent ultracentrifu- 
gation at 105,000 $\mathrm{g}$ for 1 hour. The protein content of resultant supernatants was quantified using the Bradford assay, measuring absorbance at $595 \mathrm{~nm}$ in a Synergy HTX spectrophotometer (BioTek, Vermont, USA). Samples were stored at $-80^{\circ} \mathrm{C}$.

A)

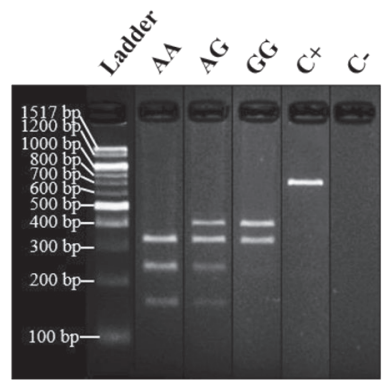

B)

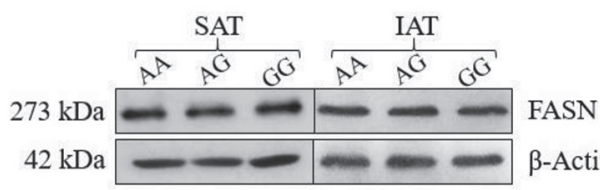

Figure 1. (A) PCR-RFLP assay (agarose gel 1.5\%,) showing AA, AG and GG genotypes, positive and negative controls (C+, C-). (B) Western Blot assessing FASN presence in samples of subcutaneous adipose tissue (SAT) and intramuscular adipose tissue (IAT)

\section{Western Blot assay for assessing the efficiency of FASN enzyme extraction}

After the ultracentrifugation step $(105,000 \mathrm{RCF})$ for protein extraction, $10 \mathrm{sam}-$ ples of each genotype were selected and analyzed using Western blotting, in order to verify that enzyme concentrations were not different between samples. For this, 20 and $100 \mu \mathrm{g}$ of total protein from supernatant were taken from both tissues (subcutaneous adipose tissue and longissimus muscle, respectively). Samples were denatured in presence of sodium dodecyl sulfate $(80 \mathrm{mM}), \beta$-mercaptoethanol $(360 \mathrm{mM})$ and glycerol $(1.1 \mathrm{M})$, incubated at $100^{\circ} \mathrm{C}$ for 5 minutes. After that, proteins were separated in a $10 \%$ polyacrylamide gel, using electrophoresis at 100 volts for 2 and a half hours. Protein wet transference was carried out using a polyvinylidene fluoride membrane at 100 volts for 2 hours and 20 minutes. Then, using the protein ladder (Cat. \#26625, Thermo Fisher Scientific, Massachusetts, USA) as references, membranes were cut out in order to perform the immunodetection of FASN and $\beta$-actin (used as control). Membranes were then incubated with Anti-FASN (Cat. \#OAGA00799, Aviva Systems Biology, California, USA) and Anti- $\beta$-Actin (Cat. \#OAAB19522, Aviva Systems Biology, California, USA) antibodies respectively, and incubated in blot buffer (Tween $20(0.1 \%)$, bovine serum albumin $(10 \mathrm{~g} / \mathrm{L})$ and phosphate buffered saline or PBS (1M)) overnight in constant stirring (125 RPM). After incubation, membranes were washed out 4 times for 5 minutes with PBS (1X) and then incubated in buffer blot for 30 minutes in presence of a secondary antibody conjugated to radish peroxidase and then washed 4 times with PBS (1X). Visualization was performed using the SuperSignal ${ }^{\text {TM }}$ West Pico PLUS (Cat. \#34578, Thermo Fisher Scientific, Massachusetts, USA) following the manufacturer instructions, obtaining a chemiluminescent reaction. Membrane bands were revealed using generic $\mathrm{x}$-ray plates. Results were normalized and assessed with the software ImageJ v1.50. 
Data was processed using the ANOVA test to identify differences $(\mathrm{P}<0.05)$ in the enzyme content between samples.

\section{Enzyme activity test}

The FASN activity assay was carried out following the method described by Kumar and Dodds (1981). Briefly, the FASN activity was assessed indirectly by measuring the decrease in the absorbance of NADPH at $340 \mathrm{~nm}$ by spectrophotometry in a 24 well plate in presence of Acetyl-CoA, Malonyl-CoA, and NADPH. The assay mixture was compounded by $100 \mu \mathrm{g}$ of total protein extract, potassium phosphate buffer (100 mM at pH 7.0), EDTA $(100 \mu \mathrm{M})$, Dithiothreitol (1 mM), NADPH $(125 \mu \mathrm{M})$, Acetyl-CoA $(25 \mu \mathrm{M})$ and Malonyl-CoA $(50 \mu \mathrm{M})$. The mixture containing all ingredients but Acetyl-CoA and Malonyl-CoA, was preincubated at $37^{\circ} \mathrm{C}$ for 8 minutes. After this stabilization, $25 \mu \mathrm{M}$ of Acetyl-CoA were added, setting a background rate of NADPH oxidation at $340 \mathrm{~nm}$ at $37^{\circ} \mathrm{C}$. After two minutes of stabilization, $50 \mu \mathrm{M}$ of Malonyl-CoA was added to the mix to start the synthesis of fatty acids and the oxidation of NADPH to NADP by FASN. The oxidation of NADPH was evaluated by quantifying the reduction in the absorbance at $340 \mathrm{~nm}$ for 2, 6, 10 and 15 minutes after the reaction started, and comparing it with a calibration curve. Measurements were made in a Synergy HTX spectrophotometer (BioTek, Vermont, USA). The quantity of enzyme that oxidizes $1 \mathrm{nmol}$ of NADPH per minute is defined as one unit of enzymatic activity (U) (Kumar and Dodds, 1981) and the specific activity is defined as the units of enzymatic activity per milligram of total protein (U/mg).

\section{Fatty acid analysis}

Total lipids were extracted from the longissimus muscle (intramuscular adipose tissue) and subcutaneous adipose tissue according to the method described by Folch et al. (1957). Fatty acids were submitted to cold methylation method in presence of $\mathrm{KOH}$, methanol and hexane. The fatty acids methyl esters were analyzed using a Clarus 500 gas chromatograph (Perkin Elmer, USA) equipped with an autosampler, a SP ${ }^{\mathrm{TM}}$ Fused Silica Capillary Column $2380(60 \mathrm{~m} \times 0.25 \mathrm{~mm} \times 0.2 \mu \mathrm{m}$ film thickness, Supelco, USA) and coupled with a flame ionization detector (FID, Perkin Elmer, USA). Nitrogen was used as carrier gas with a flow rate of $45 \mathrm{~mL} / \mathrm{min}$. The temperature program was set as follows: pre-heating at $150^{\circ} \mathrm{C}$ for $1 \mathrm{~min}$ followed by an increase of temperature at a rate of $1^{\circ} \mathrm{C} / \mathrm{min}$ up to $168^{\circ} \mathrm{C}$ (kept for 11 minutes), and a final increase of temperature at a rate of $6^{\circ} \mathrm{C} / \mathrm{min}$ up to reach $230^{\circ} \mathrm{C}$ (kept for 8 minutes), in final cycle of $48.3 \mathrm{~min}$.

\section{In-silico simulation of wildtype and mutated FASN}

In order to understand the effect of $F A S N$ g.17924A $>$ G SNP in the protein structure, leading to a possible change in enzyme activity, an in-silico simulation was performed based on the amino acid sequence corresponding to the enzyme fatty acid synthase A of Bos taurus (ID: Q71SP7), downloaded from the UNIPROT database (https://www.uniprot.org/) (The UniProt, 2018). Subsequently, an in-silico mutation was performed in one amino acid that consisted in the change of $\mathrm{T}^{-2264}$ for $\mathrm{A}^{-2264}$. 
Both protein sequences, mutated (FASN ${ }^{-}$) and wild (FASN), were modeled with the RaptorX program (Källberg et al., 2012). The stereochemical quality and accuracy of the generated models was evaluated using the SWISS-Model server to analyze the Ramachandran plot (Waterhouse et al., 2018). A molecular docking algorithm based on shape complementarity principles was used on the PATCHDOCK server to perform protein-protein docking simulations with FASN/FASN, FASN/FASN ${ }^{-}$ and FASN-/FASN- dimers (Schneidman-Duhovny et al., 2005). The ten best docking models generated by this program were refined with the FireDock program (Mashiach et al., 2008). After that, the 4 most favorable models and their global energy (GE) per genotype were selected and averaged. Generated models were then visualized with PyMOL software (The PyMOL Molecular Graphics System, Version 2.0 Schrödinger, LLC).

\section{Statistical analysis}

An analysis of variance (ANOVA) was performed using the SPSS v.23 statistical package (IBM, USA). The model was set comparing enzyme activity and fatty acid composition of intramuscular fat from longissimus muscle and subcutaneous adipose tissue, using the genotype of FASN g.17924A>G SNP as factor, with a confidence interval of $95 \%(\mathrm{P}=0.05)$. A Pearson correlation was performed comparing the relationship between backfat thickness, intramuscular fat percentage and FASN activity from subcutaneous and intramuscular adipose tissue.

\section{Results}

The mean whole hot carcass weight of animals was $311.5 \pm 13.5 \mathrm{~kg}$, with a backfat thickness mean of $2.64 \pm 0.8 \mathrm{~cm}$ and intramuscular fat percentage mean of $2.9 \pm 1.0 \%$.

\section{Genotyping}

Genotypes are shown in Table 1. All three genotypes of FASN g.17924A $>$ G SNP were represented in this study. The AG genotype was found in a higher frequency than the others in sampled animals, while the wild type genotype (AA) had the lowest frequency. The mutated allele was found to occur at a frequency of about $62 \%$ within the sampled population.

Table 1. Genotypic and allelic frequencies for FASN g.17924A>G SNP

\begin{tabular}{l|c|c|c|c|c}
\hline & \multicolumn{3}{|c|}{ Genotypic frequencies (\%) } & \multicolumn{2}{c}{ Allelic frequencies (\%) } \\
\cline { 2 - 6 } & $\mathrm{AA}(n=24)$ & $\mathrm{AG}(n=98)$ & $\mathrm{GG}(n=74)$ & $\mathrm{A}$ & $\mathrm{G}$ \\
\hline Holstein Friesian & 12.3 & 50 & 37.7 & 38 & 62 \\
\hline
\end{tabular}

\section{FASN enzyme extraction efficiency}

Results for Western Blotting of FASN enzyme extract are shown in Figure 1 B. These results indicate that FASN was present in the ultracentrifugation step super- 
natant (105,000 RCF) obtained from both tissues. Bands were observed at $273 \mathrm{kDa}$ for the FASN enzyme and at $42 \mathrm{kDA}$ for $\beta$-Actin. B-Actin was used as control, indicating that the same amount of sample was set in all wells. No differences in FASN concentration were found between samples.

\section{Enzymatic activity assay}

The FASN enzyme activity in subcutaneous adipose tissue differed among all three genotypes $(\mathrm{P}<0.05)$, with the wildtype genotype having the greatest activity $(\mathrm{AA}=273.4 \pm 69.4 \mathrm{U} / \mathrm{mg}$ ), and the heterozygous genotype having the lowest activity $(\mathrm{AG}=98.6 \pm 23.1 \mathrm{U} / \mathrm{mg})$, while the mutated homozygote had an intermediate level of activity between the other two $(\mathrm{GG}=174.68 \pm 13.7 \mathrm{U} / \mathrm{mg})$ (Figure $2 \mathrm{~A})$. The FASN activity in intramuscular adipose tissue (Figure $2 \mathrm{~B}$ ), did not differ between genotypes $(\mathrm{AA}=11.71 \pm 3.3 \mathrm{U} / \mathrm{mg}, \mathrm{AG}=7.80 \pm 4.4 \mathrm{U} / \mathrm{mg}, \mathrm{GG}=8.12 \pm 1.8 \mathrm{U} / \mathrm{mg})$.

A)

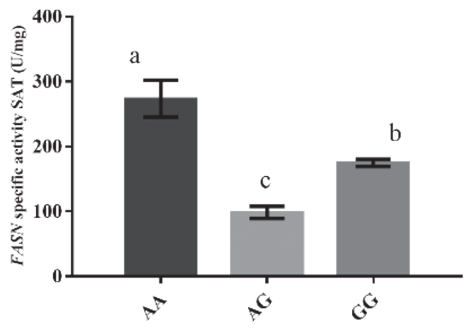

B)

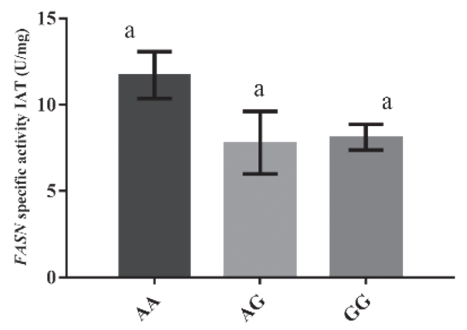

Figure 2. Effect of $F A S N$ g.17924A $>$ G SNP on FASN enzyme specific activity (U/mg) in Holstein Friesian steers. A: activity of fatty acid synthase measured in subcutaneous adipose tissue (SAT). B: activity of fatty acid synthase measured in intramuscular adipose tissue (IAT). Columns with different letters differ significantly $(\mathrm{P}<0.05)$

\section{Fatty acid profile}

The myristic acid (C14:0) percentage did not differ between genotypes in subcutaneous adipose tissue $(\mathrm{P}>0.05)$. However, the percentage of palmitic $(\mathrm{C} 16: 0)$ and stearic (C18:0) acid content was significantly different for this tissue. The percentage of palmitic acid was lower $(\mathrm{P}<0.05)$ when heterozygous genotype $(\mathrm{AG})$ was present, while the content of stearic acid was higher for the same genotype (Table 2). No additional differences were found among other fatty acids when comparing the genotypes in subcutaneous adipose tissue.

In the intramuscular adipose tissue, the percentage of myristic acid was different $(\mathrm{P}<0.05)$ between genotypes, where the AA genotype had a higher value $(2.39 \pm 0.4)$ and the GG genotype the lowest value (1.73 \pm 0.4$)$. Also, a statistical difference $(\mathrm{P}<0.05)$ was found within both the percentage of polyunsaturated fatty acids (PUFAs) (AA: 7.58 $\pm 2.03 \%$; AG: $12.63 \pm 3.83 \%$; GG: $10.93 \pm 2.53 \%$ ) and the ratio PUFA:SFA (AA: $0.14 \pm 0.04$; AG: $0.25 \pm 0.08 ; 0.21 \pm 0.05$ ) of this tissue. 
Table 2. Percentages (\%) for C14:0, C16:0 and C18:0 fatty acids according to FASN g.17924A>G genotypes of subcutaneous adipose tissue

\begin{tabular}{lcccc}
\hline & $\mathrm{AA}(N=20)$ & $\mathrm{AG}(N=20)$ & $\mathrm{GG}(N=20)$ \\
\hline C14:0 (myristic fatty acid) & $3.57 \pm 0.4$ & $3.52 \pm 0.6$ & $3.21 \pm 0.3$ \\
C16:0 (palmitic fatty acid) & $26.93 \pm 1.7 \mathrm{a}$ & $23.21 \pm 1.8 \mathrm{~b}$ & $26.63 \pm 0.7 \mathrm{a}$ \\
C18:0 (stearic fatty acid) & $22.87 \pm 0.9 \mathrm{a}$ & $26.24 \pm 1.9 \mathrm{~b}$ & $23.61 \pm 3.6 \mathrm{ab}$ \\
\hline
\end{tabular}

Values in rows with different letters differ significantly $(\mathrm{P}<0.05)$.

Table 3. Percentages (\%) for C14:0, C16:0 and C18:0 fatty acids according to FASN g.17924A>G genotypes of intramuscular adipose tissue

\begin{tabular}{l|c|c|c}
\hline & AA $(N=20)$ & AG $(N=20)$ & GG $(N=20)$ \\
\hline C14:0 (myristic fatty acid) & $2.39 \pm 0.4 \mathrm{a}$ & $1.95 \pm 0.3 \mathrm{ab}$ & $1.73 \pm 0.4 \mathrm{~b}$ \\
C16:0 (palmitic fatty acid) & $26.78 \pm 2.6$ & $25.92 \pm 1.9$ & $25.91 \pm 0.9$ \\
C18:0 (stearic fatty acid) & $22.33 \pm 1.2$ & $20.39 \pm 1.7$ & $22.16 \pm 2.7$ \\
\hline
\end{tabular}

Values in rows with different letters differ significantly $(\mathrm{P}<0.05)$.

Finally, we found a significant Pearson correlation $(\mathrm{P}<0.05)$ between the FASN enzyme activity of both tissues and intramuscular fat percentage $(\mathrm{R}=0.53$ for SAT and $\mathrm{R}=0.55$ for IAT) and between FASN activity from SAT and FASN activity from IAT $(\mathrm{R}=0.57)($ Table 4$)$.

Table 4. Pearson correlation between backfat thickness, intramuscular fat percentage and FASN activity from subcutaneous and intramuscular adipose tissue

\begin{tabular}{l|c|c|c|c}
\hline & BFT & IMF\% & FASN activity SAT & FASN activity IAT \\
\hline BFT & 1 & & & \\
IMF $(\%)$ & 0.23 & 1 & 1 & \\
FASN activity SAT & 0.39 & $0.53^{*}$ & $0.57^{*}$ & 1 \\
FASN activity IAT & -0.05 & $0.55^{*}$ & & \\
\hline
\end{tabular}

BFT: backfat thickness, IMF\%: intramuscular fat percentage, SAT: subcutaneous adipose tissue, IAT: intramuscular adipose tissue.

*correlation is significant at level 0.05 (bilateral).

\section{In-silico simulation of wildtype and mutated FASN}

All three possible genotypes for the FASN enzyme were successfully simulated in-silico. Figure 3 shows Ramachandran plots obtained from RaptorX which show the structural differences induced by the amino acid substitution in wildtype (left) and mutated (right) enzyme monomers, and Figure 4 shows predicted interactions, made by FireDock, among 3 possible dimers (Figure $4 \mathrm{~A}-\mathrm{C}$ ) and the structural changes that these interactions made.

The GE values calculated by the FireDock program when monomers interacted, were $-9.07,2.88$ and $1.37 \mathrm{kcal} \mathrm{mol}^{-1}$ for wildtype dimer, heterodimer and mutated dimer, respectively. 

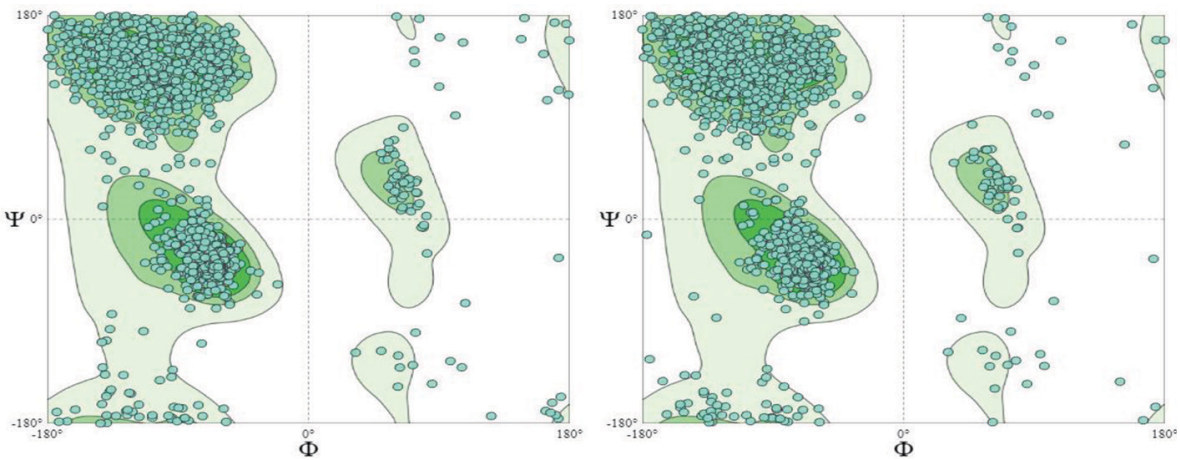

Figure 3. Ramachandran plots of FASN homodimers, wildtype (right) and mutated (left), showing a general view of possible secondary structure of the polypeptide and distribution of residues in favorable areas

A)

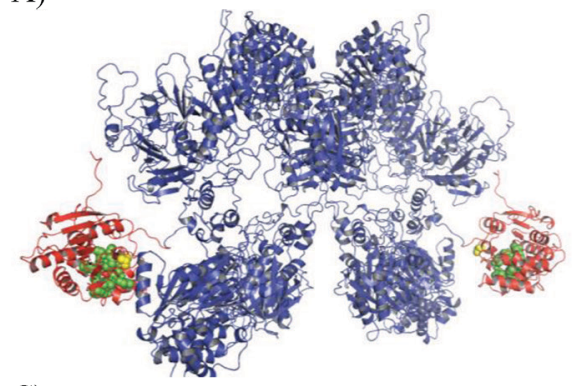

C)

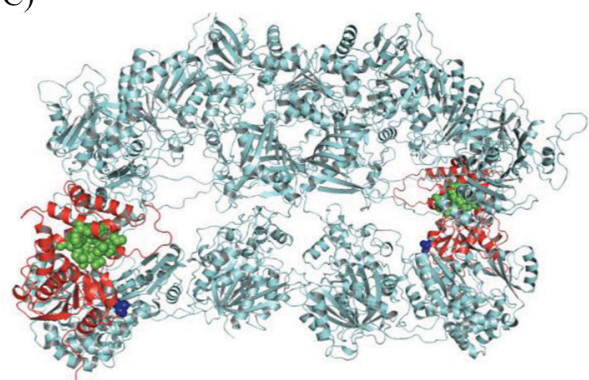

B)

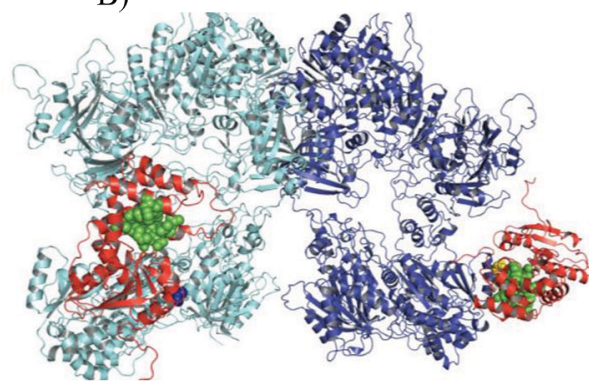

Figure 4. Predicted protein-protein docking performed with FASN models (FASN in royal blue and FASN- in cyan). FASN/FASN (A), FASN/FASN- (B) and FASN-/FASN- (C).

Red: thioesterase domain; Green: catalytic residues of thioesterase domain; Yellow and blue: position 2264 where amino acid substitution is located (Threonine/Alanine, respectively)

\section{Discussion}

\section{Genotyping}

Comparing the allelic frequencies for $F A S N$ g.17924A $>$ G SNP found in Holstein Friesian steers, which is a breed with poor conformation and fatness versus 
Aberdeen Angus, the most popular meat cattle breed, with good fat deposition and conformation (Bureš and Barton̆, 2018), it is important to highlight that there is an opposite distribution of alleles for this SNP. In Holstein Friesian, the G allele has the highest frequency (62\%), while in Aberdeen Angus it is the A allele (69\%) (Papaleo Mazzucco et al., 2016). This could be in part an explanation for the differences in the fat deposition between both breeds and makes more graphic the effect of genetic assisted selection based on polymorphisms in animal breeding, and also for the different distribution of polymorphisms among different breeds.

\section{FASN enzyme activity}

There are studies assessing FASN enzyme activity in Holstein Friesian cattle related to milk production but there is no information about the impact on meat production in this breed (Matsumoto et al., 2012; Morris et al., 2007).

The SNP g.17924A $>$ G has recently been reported to have a significant effect increasing the marbling in Korean cattle (Oh et al., 2018), but how this SNP induces this effect remains unclear. It has been hypothesized that this SNP could have an effect on FASN enzyme activity as a result of a change in protein sequence and structure caused by the SNP associated amino acid replacement. The monomers of FASN are known to be catalytically inactive while heterodimers with a mutated subunit show dramatically reduced enzyme activity compared to parental homodimers (Joshi et al., 2003). This trend was observed in the results with heterozygous genotype individuals showing less enzyme activity than those with either homozygous genotype. The differences in FASN enzyme activity in this study were found in subcutaneous adipose tissue but not in the intramuscular adipose tissue, probably due to the extreme leanness of the longissimus muscle, and the lack of marbling.

It is known from ruminants this enzyme has the greatest expression level at the adipose tissue and the lowest in muscle (Roy et al., 2005), so the leanness of the muscle and the low presence of this enzyme compared to other proteins in the intramuscular adipose tissue could be the reason why significant differences were not found in activity levels for this tissue. However, the trend of the activity observed for IAT was similar to SAT.

In beef cattle breeds the activity of FASN enzyme has been reported to be greater in Aberdeen Angus, which is a breed with a good marbling and fat deposition (Lunt et al., 1993), intermediate in Japanese Black $\times$ Angus, and lower in Limousin, which is a continental breed with good muscling but low marbling and fat deposition (Bonnet et al., 2007)

Other study reports the activity of FASN to be 3 times higher in the subcutaneous adipose tissue than in longissimus muscle and up to 30 times higher when comparing subcutaneous adipose tissue with the semitendinosus muscle (Bonnet et al., 2007).

In this study, FASN activity was, on average, 20 times higher in subcutaneous adipose tissue than in intramuscular adipose tissue, showing the same trend reported by Bonnet et al. (2007).

There is a direct relation between FASN activity and fat deposition as shown by the Pearson correlation between FASN activity and intramuscular fat percentage (Table 4). Jensen-Urstad and Semenkovich (2012) reported that reductions in FASN 
activity caused by chemical inhibition have been shown to cause dramatic reductions in fat deposition in mice. This explains why longissimus muscle samples, which have 20 times lower FASN activity than subcutaneous adipose tissue, are extremely lean and highlights that there is a direct relation between FASN activity and fat deposition.

The FASN g.17924A>G (T2264A) SNP is located in the thioesterase domain of FASN enzyme and made a change from polar, neutral, and hydrophilic to nonpolar, aliphatic, and hydrophobic in this motif, affecting the structure of the substrate binding site and therefore changing the specific activity of thioesterase domain towards C14-acyl ACP (Acyl carrier protein domain), which transfers the growing fatty acid chain throughout the different domains of this enzyme (Oh et al., 2018; Zhang et al., 2008), affecting its affinity with the fatty acid (Oztabak et al., 2014). Therefore, the thioesterase domain determines the carbon chain length of the final product of this enzyme and any change or variation in this domain could affect the fatty acid composition of meat and fat (Zhang et al., 2008). This was observed in this investigation, where this SNP effectively induces a change in the FASN activity of subcutaneous adipose tissue and in the composition of fatty acids in samples obtained from Holstein Friesian steers.

Based on what was proposed by Joshi et al. (2003), the change in protein conformation of one subunit due to an amino acid replacement will lead to a dysfunction of the enzyme, reducing the total enzyme activity in adipose tissue of animals carrying the heterozygous genotype, but only when different monomers join together, as found.

However, there are no additional references of any work assessing the effect of this specific SNP on FASN activity, therefore, this is the first insight into the effect of the FASN g.17924A>G SNP on the FASN enzyme activity.

\section{Fatty acid profile}

As reported in other studies, this SNP has an effect over the fatty acid composition of adipose tissue (Zhang et al., 2008; Li et al., 2012; Oh et al., 2012; Yeon et al., 2013; Oztabak et al., 2014), and on fat deposition, as found in Korean cattle by Oh et al. (2018), who commented that this SNP could be a casual mutation for increasing fat deposition.

In agreement with this study, Zhang et al. (2008) has reported that the Longissimus dorsi from Aberdeen Angus carrying the GG genotype had lower percentage of C14:0 fatty acid (2.92\%) compared to AA and AG genotypes (3.46 and $3.26 \%$ respectively), and the lowest percentage of $\mathrm{C} 16: 0$ fatty acid $(27.6 \%)$ compared to AA and AG genotypes (28.5\% and $28.1 \%$, respectively). In another study carried out in Korean cattle (Hanwoo breed), the AA genotype was associated with increased levels of the C14:0, C16:0, and C18:0 fatty acids, and a decrease in the C18:1 fatty acid in longissimus muscle (Oh et al., 2012).

The results showed that myristic acid in both tissues had the same trend, but differences were not significant for SAT. The AA genotype showed the greatest percentage of C14:0 and the GG genotype the lowest in both tissues. This agrees with what was published by Schennink et al. (2009), who reported that this SNP has an 
effect on milk fatty acid composition but only for the C14:0 fatty acid, while the AA genotype is the one that shows the highest percentage of this fatty acid and the GG genotype the lowest one (Schennink et al., 2009).

Palmitic acid shows the highest percentage for AA genotype and the lowest percentage for AG genotype in SAT, in agreement with the genotype which has the highest and the lowest FASN enzyme activity, respectively. The AA genotype in IAT is showing the higher percentage of C16:0, but the differences were not significant. This could occur because the variation of IMF (intramuscular fat) content depends on the ability of muscle to utilize circulating lipoprotein-associated triacylglycerols and the intracellular trafficking of fatty acids by the fatty acid-binding proteins known as FABPs (Jurie et al., 2007). Most of those FABPs bind and fix long chain fatty acids ranging from $\mathrm{C} 16: 0$ to $\mathrm{C} 20: 0$ (Storch and McDermott, 2009). Therefore, the distribution of these fatty acids in lean muscle could be most influenced by the trafficking and fixation from circulating ones rather than the novo synthesis by FASN.

Stearic fatty acid seems to have a different trend when comparing both tissues as well, this is probably due to the reduced production of palmitic acid when the AG genotype is present in subcutaneous adipose tissue. In the case of intramuscular adipose tissue, having the lowest percentage of stearic acids when the AG genotype is present could be probably due to reduced fixation of this acid by FABPs, as described by Storch and McDermott (2009), and to an increase in the proportion of unsaturated fatty acids extracted from phospholipids rather than fat because of the leanness of the longissimus muscle (Karolyi et al., 2009).

In this study, it was found that the reduced activity of the FASN enzyme when the mutation is present, especially in SAT, would reduce the production of palmitic fatty acid. This reduction, in proportion, indirectly increases the percentage of stearic fatty acids, as shown in Table 2 for the AG genotype. On the other hand, the leanness of the longissimus muscle combined with the reduced expression and activity of the enzyme in this tissue (up to 24 times less in IAT than SAT), significantly reduces the quantity of fatty acids methyl esters injected to the gas chromatograph which could decrease the sensitivity of the test for the SFA, which are even present in muscle than fat in lower percentages (Karolyi et al., 2009).

\section{In-silico simulation of wildtype and mutated FASN}

The models generated with the RaptorX program showed an excellent quality when they were evaluated with the Ramachandran plot analysis with the FASN model having $92.02 \%$ of residues in favored regions and the FASN- model having $91.76 \%$ of residues in favored regions. The Ramachandran plot is one of the most reliable methods for determining the quality of protein structures. When models have over $90 \%$ of their residues in the favored regions of the Ramachandran plot they are considered as accurate as $2 \AA$ resolution crystalline structures (Laskowski et al., 1993). Differences observed in the Ramachandran plots are explained by the change of an amino acid in the thioesterase domain of this enzyme.

Ramachandran plots have been considered as one of the most simple and most sensitive plots for assessing the quality of protein model (Kleywegt and Jones, 1996). As most of the residues are found in an allowed region it is an indicator of a high- 
-quality model (Chen et al., 2010). In addition to visualizing all the possible combinations of dihedral angles, phi (f) and psi (Y), of a polypeptide, these plots are a good tool to visualize differences between a wildtype and mutated protein (Gromiha et al., 2002).

Results obtained with FireDock showed a variation in the GE values, where the wildtype dimer of the enzyme showed the most favorable GE between its monomers and heterodimer presented the least favorable GE between its monomers, suggesting a relevant role of this mutation (T2264A) in the interaction between the FASN monomers during dimerization. This is probably due to the change from the polar, neutral, and hydrophilic properties of threonine, to the nonpolar, aliphatic, and hydrophobic properties of alanine affecting the structure of the polypeptide at the dimeric form (Oh et al., 2018).

As the lower the GE the greater the strength of the interaction, we have hypothesized that animals carrying the heterozygous genotype (AG) will have significant less activity than wildtype (AA) and mutated (GG) homozygous genotypes as a result of the monomers having a less stable and more distant join between them caused by the higher GE.

As the acyl carrier protein domain (ACP) of each subunit works with the opposite subunit during the elongation of the fatty acid in synthesis, a more distant and less stable join between subunits could impair the movement of the ACP between catalytic sites of the enzyme and decreasing the affinity with the substrate resulting in lower activity.

Both the Ramachandran plots and GE confirm that the amino acid substitution made a change in FASN structural conformation.

\section{Conclusion}

This is the first time the effect of the FASN g.17924A $>$ G SNP on FASN enzyme activity has been evaluated in Holstein Friesian steers, and it can be confirmed that there is an effect of this mutation on the enzyme activity due to the amino acid substitution in the thioesterase domain, leading to a structural variation in the dimeric form of the enzyme. This leads to a significant difference in the fatty acid composition of subcutaneous adipose tissue. Finally, the FASN enzyme activity shows to be closely related to backfat thickness and intramuscular fat percentage in this cattle breed.

\section{Acknowledgements}

The first author wishes to thank to Faenadora de Carnes Victoria S.A., and especially to Dr. María Angélica Vásquez for providing the animal samples for this study, and to CONICYT (Comisión Nacional de Investigación Científica y Tecnológica) for funding this doctoral scholarship. This investigation was supported by National Doctorate Grant CONICYT: 21151048.

The authors wish to thank Fondecyt Projects: Post doctorate Fondecyt N³190287 (John Quiñones) and Fondecyt Initiation in Research Nº11190621 (Rommy Díaz).

We also thank for the corrections and suggestions of Dr. Robert Brinzer that have helped to improve this article. 


\section{Conflicts of Interest}

The authors declare no conflicts of interest.

\section{References}

Alim M.A., Wang P., Wu X.P., Li C., Cui X.G., Zhang S.L., Zhang Q., Zhang Y., S u n D.X. (2014). Effect of FASN gene on milk yield and milk composition in the Chinese Holstein dairy population. Anim. Genet., 45: 111-113.

B hu i y a n M.S.A., Yu S.L., J e on J.T., Yo on D., Cho Y.M., P a r k E.W., K i m N.K., K i m K.S., L e e J.H. (2009). DNA polymorphisms in SREBF1 and FASN genes affect fatty acid composition in Korean cattle (Hanwoo). Asian-Australasian J. Anim. Sci., 22: 765-773.

B onnet M., Faulconnier Y., Leroux C., Jurie C., Cassar-Malek I., B a uchart D., B oulesteix P., Pethick D., Hocquette J.F., Chilliard Y. (2007). Glucose-6-phosphate dehydrogenase and leptin are related to marbling differences among Limousin and Angus or Japanese Black × Angus steers. J. Anim. Sci., 85: 2882-2894.

B u re š D., B a r to ň L. (2018). Performance, carcass traits and meat quality of Aberdeen Angus, Gascon, Holstein and Fleckvieh finishing bulls. Livest. Sci., 214: 231-237.

Chen V.B., A rendall W.B., Head d J.J., Ke edy D.A., I m mormino R.M., Ka pral G.J., Murray L.W., Richards on J.S., Richards on D.C. (2010). MolProbity: All-atom structure validation for macromolecular crystallography. Acta Crystallogr. Sect. D Biol. Crystallogr., 66: $12-21$.

Choi N.J., Enser M., Wood J.D., S c ollan N.D. (2000). Effect of breed on the deposition in beef muscle and adipose tissue of dietary n-3 polyunsaturated fatty acids. Anim. Sci., 71: 509-519.

Ciecierska D., Frost A., Grzesiak W., Proskura W.S., Dybus A., Olszewski A. (2013). The influence of fatty acid synthase polymorphism on milk production traits in Polish Holstein-Friesian cattle. J. Anim. Plant Sci., 23: 376-379.

F o l ch J., L e es M., S t a n ley G.H.S. (1957). A simple method for the isolation and purification of total lipids from animal tissues. J. Biol. Chem., 226: 497-509.

Gromiha M.M., O ob at a ke M., K on o H., U ed a ir a H., S a rai A. (2002). Importance of mutant position in Ramachandran plot for predicting protein stability of surface mutations. Biopolymers, 64: 210-220.

J e n s e n-Urst a d A.P.L., S e m e n k ovi c h C.F. (2012). Fatty acid synthase and liver triglyceride metabolism: Housekeeper or messenger? Biochim. Biophys. Acta - Mol. Cell Biol. Lipids, 1821: $747-753$.

J e on g J., K w o n E.G., I m S.K., S e o K.S., B a i k M. (2012). Expression of fat deposition and fat removal genes is associated with intramuscular fat content in longissimus dorsi muscle of Korean cattle steers. J. Anim. Sci., 90: 2044-2053.

J o s hi A.K., Rangan V.S., Witkows ki A., S mith S. (2003). Engineering of an active animal fatty acid synthase dimer with only one competent subunit. Chem. Biol., 10: 169-173.

Jurie C., Cassar-Malek I., Bonnet M., Leroux C., Bauchart D., Boulesteix P., Pethick D.W., Hocquette J.F. (2007). Adipocyte fatty acid-binding protein and mitochondrial enzyme activities in muscles as relevant indicators of marbling in cattle. J. Anim. Sci., 85: 2660-2669.

Kä 11 berg M., Wang H., Wang S., P eng J., Wang Z., Lu H., Xu J. (2012). Template-based protein structure modeling using the RaptorX web server. Nat. Protoc., 7: 1511.

Karolyi D., Dikić M., Salajpal K., Jurić I. (2009). Fatty acid composition of muscle and adipose tissue of beef cattle. Ital. J. Anim. Sci., 8: 264-266.

Kleywe gt G.J., Jones T.A. (1996). Phi/psi-chology: Ramachandran revisited. Structure, 4: 1395-1400.

K u m a r S., D o d d s P.F. (1981). Fatty acid synthase from lactating bovine mammary gland. Methods Enzymol., 71: 86-97.

Laskowski R.A., Mac Arthur M.W., Thornton J.M. (1993). PROCHECK: a program to check the stereochemical quality of protein structures. J. Appl. Crystallogr., 26: 283-291. 
Li C., Aldai N., Vinsky M., Dugan M.E.R., Mc Allister T.A. (2012). Association analyses of single nucleotide polymorphisms in bovine stearoyl-CoA desaturase and fatty acid synthase genes with fatty acid composition in commercial cross-bred beef steers. Anim. Genet., 43: 93-97.

Lunt D.K., Riley R.R., S mith S.B. (1993). Growth and carcass characteristics of Angus and American Wagyu steers. Meat Sci., 34: 327-334.

Mashiach E., Schneidman-Duhovny D., Andrusier N., Nussinov R., Wolfs o n H.J. (2008). FireDock: a web server for fast interaction refinement in molecular docking. Nucleic Acids Res., 36: 229-232.

Matsumoto H., Inada S., Kobayashi E., Abe T., Has ebe H., Sasazaki S., Oya$\mathrm{m}$ a K., M a n n e n H. (2012). Identification of SNPs in the FASN gene and their effect on fatty acid milk composition in Holstein cattle. Livest. Sci., 144: 281-284.

Morris C.A., Cullen N.G., Glas s B.C., Hyndman D.L., Manley T.R., Hickey S.M., M c E w a n J.C., P i t c h ford W.S., B o t t e m a C.D.K., L e e M.A.H. (2007). Fatty acid synthase effects on bovine adipose fat and milk fat. Mamm. Genome, 18: 64-74.

N a varro H., Go i c L. (2003). Seminario hagamos de la lechería un mejor negocio. In: Es negocio criar terneros de lecheria? Series Actas INIA No. 24, pp. 100-105.

N g - K w a i - H a n g K.F., H a y e s J.F., M ox le y J.E., M o n a r d e s H.G. (1986). Relationships between milk protein polymorphisms and major milk constituents in Holstein-Friesian cows. J. Dairy Sci., 69: 22-26.

Oh D., Lee Y., La B., Ye o J., Chung E., K im Y., L e e C. (2012). Fatty acid composition of beef is associated with exonic nucleotide variants of the gene encoding FASN. Mol. Biol. Rep., 39 : 4083-4090.

O h D.Y., N a m I., H w a ng S., K ong H., L e e H., H a J., B a i k M., O h M.H., K i m S., H a n K., et al. (2018). In vivo evidence on the functional variation within fatty acid synthase gene associated with lipid metabolism in bovine longissimus dorsi muscle tissue. Gen. Genom., 40: 289-294.

Ostrowski B., Deblitz C. (2001). La Competitividad en producción lechera de los países de Chile, Argentina, Uruguay y Brasil. Int. Farm Comp. Network.

Oztabak K., Gursel F.E., Akis I., A tes A., Yardibi H., Turkay G. (2014). FASN gene polymorphism in indigenous cattle breeds of Turkey. Folia Biol., 62: 29-35.

Papaleo Mazzucco J., Goszczynski D.E., Ripoli M.V., Melucci L.M., P a r do A.M., Colatto E., Rogberg-Muñoz A., Mezzadra C.A., Depetris G.J., Giovambat t is t a G., et al. (2016). Growth, carcass and meat quality traits in beef from Angus, Hereford and cross-breed grazing steers, and their association with SNPs in genes related to fat deposition metabolism. Meat Sci., 114: 121-129.

Par is W., Menezes L.F.G. de, Santos P.V. dos, Kus s F., S ilve ir a M.F. da, B o ito B., Venturini T., Stanqueviski F. (2015). Quantitative carcass traits of Holstein calves, finished in different systems and slaughter weights. Ciênc. Rural, 45: 505-511.

Raza S.H.A., Gui L., Khan R., Schreurs N.M., Xia oyu W., Wu S., Mei C., Wang L., $\mathrm{M}$ a X., We i D., et al. (2018). Association between FASN gene polymorphisms ultrasound carcass traits and intramuscular fat in Qinchuan cattle. Gene, 645: 55-59.

Rodríguez-Bermúdez R., Miranda M., Orjales I., Rey-Crespo F., Muñoz N., Ló pez-A lons o M. (2017). Holstein-Friesian milk performance in organic farming in north Spain: Comparison with other systems and breeds. Spanish J. Agric. Res., 15: 20.

Roy R., Taourit S., Zaragoza P., Eggen A., Rodellar C. (2005). Genomic structure and alternative transcript of bovine fatty acid synthase gene (FASN): Comparative analysis of the FASN gene between monogastric and ruminant species. Cytogenet. Genome Res., 111: 65-73.

Schennink A., Bovenhuis H., Lé on-Kloosterziel K.M., Van Arendonk J.A.M., Vi s k e r M.H.P.W. (2009). Effect of polymorphisms in the FASN, OLR1, PPARGC1A, PRL and STAT5A genes on bovine milk-fat composition. Anim. Genet., 40: 909-916.

Schneidman-Duhovny D., Inbar Y., Nussinov R., Wolfson H.J. (2005). PatchDock and SymmDock: Servers for rigid and symmetric docking. Nucleic Acids Res., 33: 363-367.

S t o r c h J., M c D e r m o t t L. (2009). Structural and functional analysis of fatty acid-binding proteins. J. Lipid Res., 50: 126-131.

The UniProt (2018). UniProt: a worldwide hub of protein knowledge. Nucleic Acids Res., 47: 506-515. Waterhouse A., Bertoni M., B i enert S., Studer G., Tauriello G., Gumienny R., 
He e r F.T., D e B e e r T.A.P., R e m p fer C., B ordoli L., et al. (2018). SWISS-MODEL: Homology modelling of protein structures and complexes. Nucleic Acids Res., 46: 296-303.

Yeon S.H., Lee S.H., Choi B.H., L e e H.J., Jang G.W., L e e K.T., Kim K.H., Lee J.H., Chung H.Y. (2013). Genetic variation of FASN is associated with fatty acid composition of Hanwoo. Meat Sci., 94: 133-138.

Zhang S., Knight T.J., Ree cy J.M., B e itz D.C. (2008). DNA polymorphisms in bovine fatty acid synthase are associated with beef fatty acid composition. Anim. Genet., 39: 62-70.

Zhu B., Niu H., Zhang W., Wang Z., Liang Y., Guan L., Guo P., Chen Y., Zhang L., G u o Y., et al. (2017). Genome wide association study and genomic prediction for fatty acid composition in Chinese Simmental beef cattle using high density SNP array. BMC Genomics, 18: 464.

Received: 10 X 2019

Accepted: 28 V 2020 